\title{
ЕКОНОМЕТРИЧНЕ МОДЕЛЮВАННЯ ПОКАЗНИКІВ ЕФЕКТИВНОСТІ ВИКОРИСТАННЯ ОСНОВНИХ ЗАСОБІВ ЛІСОГОСПОДАРСЬКОГО ПІДПРИЄМСТВА
}

За даними показників діяльності лісогосподарського підприємства, типового для Малого Полісся України, побудовано множинні регресійні моделі для таких загальних показників ефективності використання основних засобів, як фондовіддача, фондоозброєність та фондорентабельність (залежні змінні). Встановлено чинники (незалежні змінні), які впливають на значення цих показників. Проведено попередній економетричний аналіз моделей: побудовано кореляційні поля та графіки залежності між усіма незалежними та залежними змінними; розраховано парні коефіцієнти кореляції та оцінено силу (щільність) зв'язку між усіма змінними моделей; виявлено незалежні змінні, які найбільше впливають на значення фондовіддачі, фондоозброєності та фондорентабельності. За допомогою покрокового регресійного аналізу побудовано адекватні регресійні моделі. Значущість моделей загалом перевірено за $F$-статистиками Фішера-Снедекора, а параметрів моделей - за $t$-статистиками Ст'юдента 3 довірчою ймовірністю $p=0,95$. Моделі перевірено на наявність мультиколінеарності, гетероскедастичності та автокореляції. Розроблені моделі можна використати для вдосконалення планування використання основних засобів лісогосподарських підприємств Малого Полісся. Запропоновану методику також можна використати для розроблення відповідних моделей для будь-якого лісогосподарського підприємства.

Ключові слова: фондовіддача; фондоозброєність; фондорентабельність; покроковий регресійний аналіз.

Вступ. Сучасний етап розвитку ринкової економіки характеризується умовами підвищеної волатильності та загальної нестабільності. Тому саме у таких умовах підвищується важливість застосування в економіці економетричних моделей, які, на відміну від більшості інших економіко-математичних моделей, a priori включають у себе випадкову складову як невід'ємну обов'язкову частину моделі. Упродовж двох останніх десятиліть розроблено методологію та методики побудови та оцінювання економетричних моделей, які детально описано у таких роботах, як (Babeshko, 2006; Green, 2018; Gujarati, 1995; Dougherty, 2011; Zdrok \& Lagotskyi, 2010; Klebanova et al., 2010; Kozlovskyi, 2005; Magnus et al., 2005; Pindyk \& Rubinfeld, 1998) та у багатьох інших.

Стан, своєчасне оновлення та підвищення ефективності використання основних засобів на вітчизняних підприємствах є важливою та актуальною проблемою, яку досліджено у роботах таких учених, як (Larka, \& Horzhii, 2013; Pokropyvnyi, 2006), Поддєрьогін А. М., Тарасенко Н. В., Турило А. М. та ін.

За останні роки науковці НЛТУ України розробили економетричні моделі: на економічному макрорівнідля установ природно-заповідного фонду (ПЗФ) України; на мікрорівні - для окремих заповідних господарств (Henyk et al., 2011); уподобань населення щодо рекреаційних лісів Львівщини (Pelyukh \& Zahvoyska, 2018). Також на прикладі лісогосподарських під- приємств природної області Малого Полісся Львівської обл. розроблено часові моделі динаміки запасів і середніх приростів деревини основних лісотвірних порід (Shvediuk, 2018). Однак на сьогодні наразі не розроблені економетричні моделі для основних економічних показників діяльності лісогосподарських підприємств, і зокрема, показників ефективності використання основних засобів.

Метою роботи є побудова адекватних економетричних моделей загальних показників ефективності використання основних засобів на прикладі типового лісового підприємства природної області Малого Полісся.

Основними завданнями дослідження є: формування інформаційної бази; вибір економічних чинників та специфікація моделей; попередній аналіз і відбір значущих незалежних чинників; побудова шляхом покрокового регресійного аналізу адекватних моделей фондовіддачі, фондоозброєності та фондорентабельності; перевірка моделей на мультиколінеарність, гетероскедастичність та автокореляцію.

Матеріал і методи дослідження. Моделювання здійснено на прикладі типового лісогосподарського підприємства для природної області Малого Полісся, яка охоплює південну частину Рівненської і північну Львівської, Тернопільської та Хмельницької областей (Shvediuk, 2018). При виборі типового для цієї природної області підприємства використано методичний під-

\section{Інформація про авторів:}

Геник Оксана Володимирівна, канд. екон. наук, доцент, кафедра економіки підприємства. Email: yarhenyk@gmail.com; https://orcid.org/0000-0003-3887-0581

Козловський Сергій Олександрович, канд. екон. наук, доцент кафедри економіки підприємства. Email: Kozlovsky@nltu.edu.ua

Цитування за ДСтУ: Геник О. В., Козловський С. О. Економетричне моделювання показників ефективності використання основних засобів лісогосподарського підприємства. Науковий вісник НлтУ України. 2019, т. 29, № 4. С. 28-32.

Citation APA: Henyk, O. V., \& Kozlovskyi, S. O. (2019). Econometric modeling of indicators of efficiency of use of fixed assets of a forestry enterprise. Scientific Bulletin of UNFU, 29(4), 28-32. https://doi.org/10.15421/40290405 
хід до визначення модельних підприємств лісового господарства, запропонований науковцями Українського НДІ лісового господарства i агромеліорації ім. Г. М. Висоцького (Torosov, 2018), згідно з яким проводять міжгосподарський економічний аналіз за низкою показників. Ми здійснили порівняльний аналіз трьох підприємств (ДП "Буське ЛГ", ДП "Жовківське ЛГ" та ДП "Радехівське ЛМГ") за 2016-2018 рр. за такими основними показниками діяльності: загальна площа Держлісфонду; заготівля деревини, зокрема і від рубок головного користування; обсяг реалізації продукції на внутрішньому і зовнішньому ринках; обсяг перероблення деревини на власних виробничих потужностях; обсяг продукції перероблення; витрати на ведення лісового господарства; чисельність штатних працівників; середньомісячна заробітна плата. За результатами аналізу виявлено, що типовим лісогосподарським підприємством для природної області Малого Полісся Львівщини $є$ ДП "Жовківське ЛГ". Тому для розроблення моделей використано дані про діяльність цього підприємства за 2013-2017 pp. 3 поквартальною розбивкою. Зокрема, використано такі форми Державної статистичної звітності: Баланс (форма 1); Звіт про фінансові результати (форма 2); Примітки до річної фінансової звітності (форма 5); Звіт про виробництво продукції (форма 1ПНПП); Звіт з праці (форма 1-ПВ). Окрім цього, використано інформацію про основні показники діяльності ДП "Жовківське ЛГ", яку щоквартально готують і розміщують на офіційному сайті підприємства.

Побудову й оцінювання моделей здійснено за допомогою методики економетричного моделювання, розробленої і апробованої авторами на установах ПЗФ України (Henyk et al., 2011). Перевірку моделей на мультиколінеарність, гетероскедастичність та автокореляцію проведено за допомогою спеціальних тестів (Gujarati, 1995; Dougherty, 2011; Zdrok \& Lagotskyi, 2010). Для розрахунків використано інструменти пакету "Аналіз даних" Microsoft Excel.

Результати дослідження. До загальних показників ефективності використання основних засобів (O3) відносять фондовіддачу $\left(y_{1}\right)$ або фондомісткість (показник, обернений до фондовіддачі), фондоозброєність $\left(y_{2}\right)$ та фондорентабельність $\left(y_{3}\right)$ (Pokropyvnyi, 2006). Будемо називати ці показники залежними або пояснювальними змінними. До чинників, що впливають на ці показники (незалежні або пояснювальні змінні), віднесемо такі: $x_{1}$ - заготівля деревини; $x_{2}$ - обсяг продукції перероблення; $x_{3}$ - чистий дохід від реалізації продукції; $x_{4}-$ ceредньомісячна заробітна плата. Тоді рівняння множинної регресії матимуть вигляд:

Модель 1. Залежна змінна $y_{1}-$ фондовіддача:

$$
y_{1}=b_{0}+b_{1} \cdot x_{1}+b_{2} \cdot x_{2}+b_{3} \cdot x_{3}+b_{4} \cdot x_{4} \text {. }
$$

Модель 2. Залежна змінна $y_{2}-$ фондоозброєність:

$$
y_{2}=b_{0}+b_{1} \cdot x_{1}+b_{2} \cdot x_{2}+b_{3} \cdot x_{3}+b_{4} \cdot x_{4} \text {. }
$$

Модель 3. Залежна змінна $y_{3}$ - фондорентабельність:

$$
y_{3}=b_{0}+b_{1} \cdot x_{1}+b_{2} \cdot x_{2}+b_{3} \cdot x_{3}+b_{4} \cdot x_{4},
$$

де $b_{0}, b_{1}, b_{2}, b_{3}$ - оцінки коефіцієнтів регресії.

Для забезпечення економетричного моделювання сформовано інформаційну базу, яка містить щоквартальні спостереження за 5 років усіх зазначених залежних та незалежних змінних, тобто обсяги вибірок 3 них, $n=20$. Проведено попередній економетричний аналіз моделей (1)-(3). Для цього, по-перше, для визначення сили (тісноти) зв'язку кожної залежної з усіма незалежними змінними, розраховано коефіцієнти парної кореляції (табл. 1).
Табл. 1. Парні коефіцієнти кореляції для показників використання О3

\begin{tabular}{|c|c|c|c|c|}
\hline$Y-X$ & $x_{1}$ & $x_{2}$ & $x_{3}$ & $x_{4}$ \\
\hline$y_{1}$ & 0,01 & 0,8174 & 0,9113 & 0,9667 \\
\hline$y_{2}$ & 0,024 & 0,5572 & 0,519 & 0,8224 \\
\hline$y_{3}$ & $-0,044$ & 0,3319 & 0,6683 & 0,8224 \\
\hline
\end{tabular}

Проаналізувавши дані табл. 1, можна зробити такі висновки щодо наявності і сили зв'язку між незалежними $\left(x_{1}, x_{2}, x_{3}, x_{4}\right)$ і залежними $\left(y_{1}, y_{2}, y_{3}\right)$ змінними. Так, об'єми заготівлі деревини $\left(x_{1}\right)$ практично не впливають на фондовіддачу, фондоозброєність та фондорентабельність. У обсягів продукції перероблення деревини $\left(x_{2}\right)$ існує сильний зв'язок із фондовіддачею $\left(y_{1}\right)$, середній 3 фондоозброєністю $\left(y_{2}\right)$ і слабкий - 3 фондорентабельністю $\left(y_{3}\right)$. У чистого доходу від реалізації продукції існує $\left(x_{3}\right)$ сильний зв'язок із фондовіддачею $\left(y_{1}\right)$, а $з$ фондоозброєністю $\left(y_{2}\right)$ і фондорентабельністю $\left(y_{3}\right)$ - середній. Між середньомісячною зарплатою $\left(x_{4}\right)$ і трьома показниками використання основних засобів $\left(y_{1}, y_{2}, y_{3}\right)$ iснує сильний кореляційний зв'язок.

По-друге, побудовано кореляційні поля та графіки залежності пояснювальних змінних від незалежних чинників. На рис. 1-6 подано графіки рівнянь регресії тільки для тих незалежних змінних, де коефіцієнт детермінації $R^{2}>0,5$.

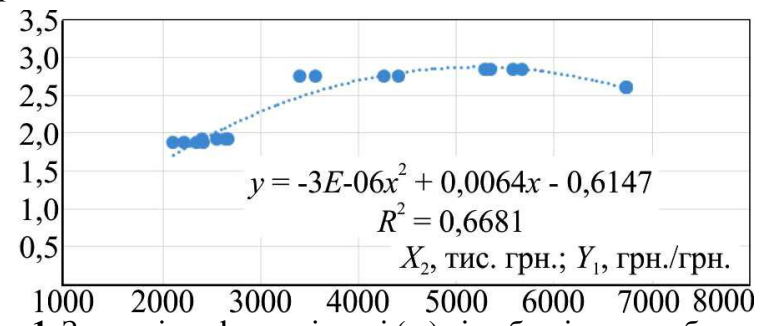

Рис. 1. Залежність фондовіддачі $\left(y_{1}\right)$ від обсягів перероблення деревини $\left(x_{2}\right)$

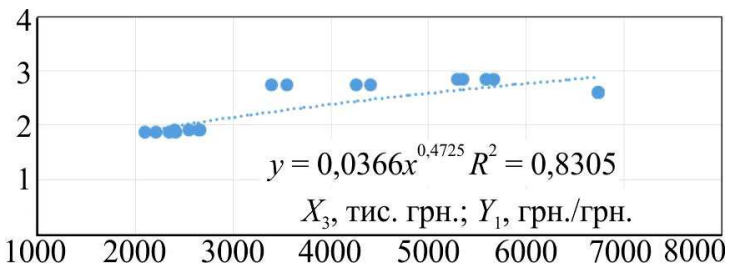

Рис. 2. Залежність фондовіддачі $\left(y_{1}\right)$ від чистого доходу $\left(x_{3}\right)$

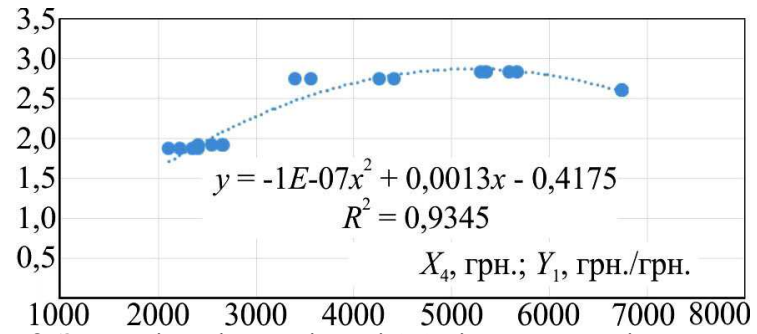

Рис. 3. Залежність фондовіддачі $\left(y_{1}\right)$ від середньомісячної заробітної плати $\left(x_{4}\right)$

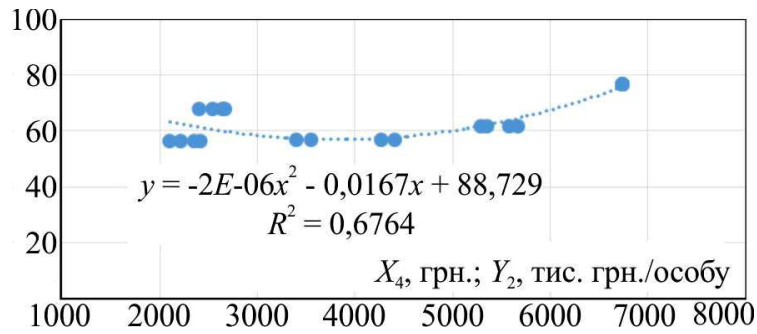

Рис. 4. Залежність фондоозброєності $\left(y_{2}\right)$ від середньомісячної заробітної плати $\left(x_{4}\right)$ 


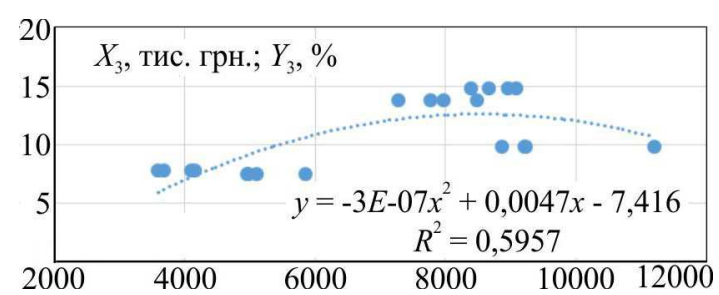

Рис. 5. Залежність фондорентабельності $\left(y_{3}\right)$ від чистого доходу $\left(x_{3}\right)$

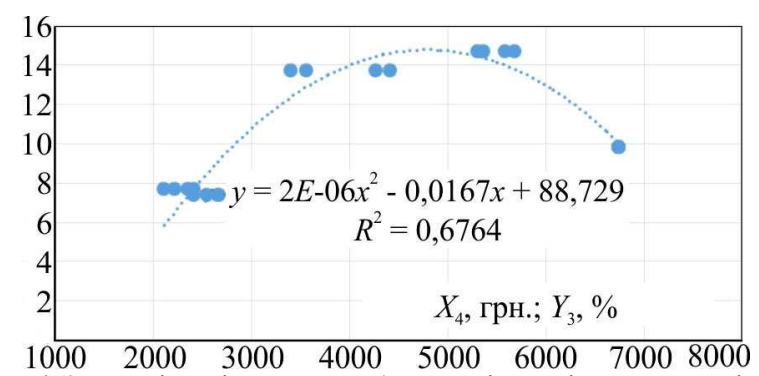

Рис. 6. Залежність фондорентабельності $\left(y_{3}\right)$ від середньомісячної заробітної плати $\left(x_{4}\right)$
Унаслідок попереднього аналізу ті незалежні змінні, які не впливають на пояснювальні або впливають слабо, вилучені з початкових моделей, котрі тепер можна подати так:

$$
\begin{gathered}
y_{1}=b_{0}+b_{2} \cdot x_{2}+b_{3} \cdot x_{3}+b_{4} \cdot x_{4} ; \\
y_{2}=b_{0}+b_{2} \cdot x_{2}+b_{3} \cdot x_{3}+b_{4} \cdot x_{4} ; \\
y_{3}=b_{0}+b_{3} \cdot x_{3}+b_{4} \cdot x_{4} .
\end{gathered}
$$

Розрахунок параметрів моделей (4)-(6) проведено за допомогою інструменту REGRESSION пакету Аналіз даних. При цьому застосовано прочедуру покрокового вилучення змінних (Kozlovskyi, 2005). Результати розрахунків та оцінювання моделей подано в табл. 2-4.

Отже, внаслідок застосування покрокового регресійного аналізу отримано такі моделі:

- фондовіддачі: $y_{1}^{2}=1,2941-0,0007 \cdot x_{2}+0,002 \cdot x_{3}$;

- фондоозброєності: $y_{2}^{3}=52,287+0,0027 \cdot x_{4}$;

- фондорентабельності: $y_{3}^{2}=4,2489+0,0009 \cdot x_{3}$.

Табл. 2. Економетричне оцінювання моделей фондовіддачі

\begin{tabular}{|c|c|c|c|}
\hline Модель оновлення О3 & Коефіцієнти кореляції та детермінації & $F$-статистика & $t$-статистика \\
\hline $\begin{array}{c}y_{1}^{1}=1,2734-0,0007 \cdot x_{2} \\
+0,0002 \cdot x_{3}-0,00005 \cdot x_{4}\end{array}$ & $R=0,9221 ; R^{2}=0,8502 ; \bar{R}^{2}=0,8221$ & $F=30,27>3,24$ & $\begin{array}{c}t_{0}=8,87>2,12 ; t_{2}=|-2,53|>2,12 ; \\
t_{3}=5,097>2,12 ; t_{4}=|-0,466|<2,12\end{array}$ \\
\hline$y_{1}^{2}=1,2941-0,0007 \cdot x_{2}+0,002 \cdot x_{3}$ & $R=0,9210 ; R^{2}=0,8482 ; \bar{R}^{2}=0,8303$ & $F=47,48>3,59$ & $\begin{array}{c}t_{0}=0,7<2,11 ; t_{3}=|-2,63|>2,11 ; \\
t_{4}=7,48>2,11\end{array}$ \\
\hline
\end{tabular}

Табл. 3. Економетричне оцінювання моделей фондоозброєності

\begin{tabular}{|c|c|c|c|}
\hline \multicolumn{2}{|c|}{ Табл. 3. Економетричне оцінювання моделей фондоозбросності } \\
\hline $\begin{array}{c}y_{2}^{1}=54,1658+0,0146 \cdot x_{2}-0,0028 \cdot x_{3} \\
+0,0045 \cdot x_{4}\end{array}$ & Коефіцієнти кореляції та детермінації & $F$-статистика & $t$-статистика \\
\hline$y_{2}^{2}=55,7835-0,0016 \cdot x_{3}+0,0047 \cdot x_{4}$ & $R=0,6400 ; R^{2}=0,4095 ; \bar{R}^{2}=0,3401$ & $F=5,89>3,59$ & $\begin{array}{c}t_{0}=11,0>2,11 ; t_{3}=|-1,06|<2,11 ; \\
t_{4}=2,33>2,11\end{array}$ \\
\hline$y_{2}^{3}=52,287+0,0027 \cdot x_{4}$ & $R=0,6087 ; R^{2}=0,3706 ; \bar{R}^{2}=0,3356$ & $F=10,59>4,41$ & $t_{0}=13,67>2,101 ; t_{4}=3,25>2,101$ \\
\hline
\end{tabular}

Табл. 4. Економетричне оцінювання моделей фондорентабельності

\begin{tabular}{|c|c|c|c|}
\hline Модель оновлення О3 & Коефіцієнти кореляції та детермінації & $F$-статистика & $t$-статистика \\
\hline$y_{3}^{1}=0,3043-0,0013 \cdot x_{3}+0,0047 \cdot x_{4}$ & $R=0,4758 ; R^{2}=0,5057 ; \bar{R}^{2}=0,4475$ & $F=8,69>3,59$ & $\begin{array}{c}t_{0}=1,93<2,11 ; t_{3}=2,93>2,11 ; \\
t_{4}=|-1,425|<2,11\end{array}$ \\
\hline$y_{3}^{2}=4,2489+0,0009 \cdot x_{3}$ & $R=0,6683 ; R^{2}=0,4466 ; \bar{R}^{2}=0,4157$ & $F=14,52>4,41$ & $t_{0}=2,409>2,101 ; t_{3}=3,812>2,101$ \\
\hline
\end{tabular}

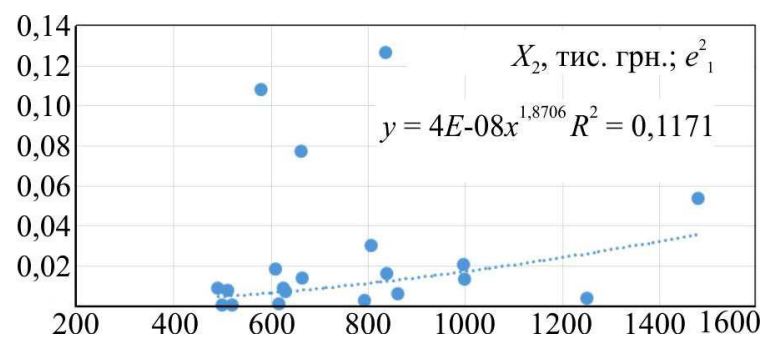

Рис. 7. Залежність квадратів відхилень фондовіддачі $\left(e_{1}^{2}\right)$ від обсягів перероблення деревини $\left(x_{2}\right)$

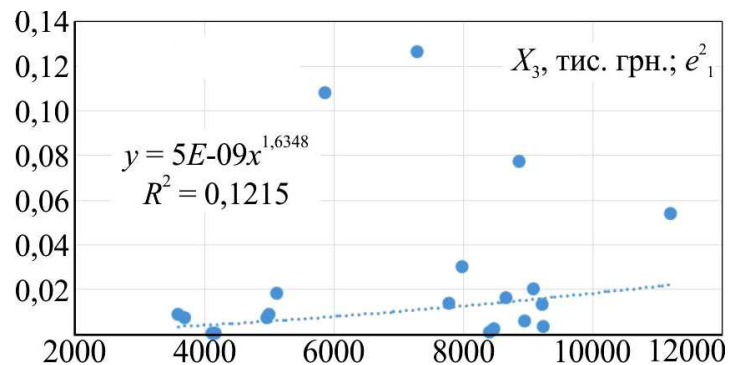

Рис. 8. Залежність квадратів відхилень фондовіддачі $\left(e_{1}^{2}\right)$ від чистого доходу $\left(x_{3}\right)$

Моделі (7)-(9) перевірено на наявність гетероскедастичності і автокореляції, а модель (7) - мультиколінеарності.

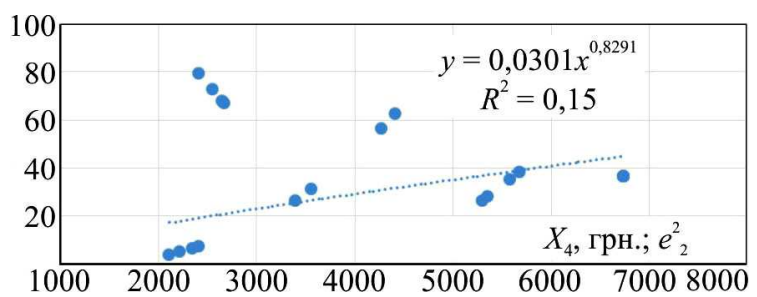

Рис. 9. Залежність квадратів відхилень фондоозброєності $\left(e_{2}^{2}\right)$ від середньомісячної заробітної плати $\left(x_{4}\right)$

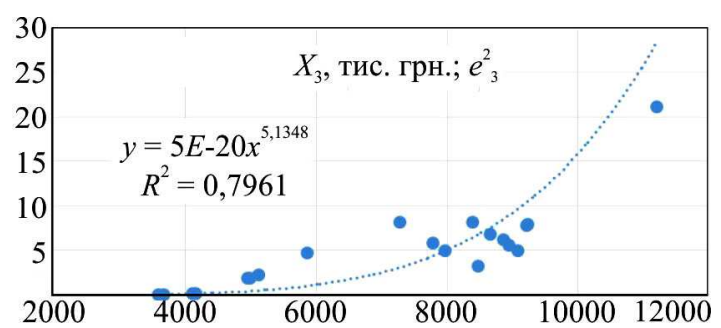

Рис. 10. Залежність квадратів відхилень фондорентабельності $\left(e_{3}^{2}\right)$ від чистого доходу $\left(x_{3}\right)$

Моделі (7)-(9) перевірено на наявність гетероскедастичності і автокореляції, а модель (7) - мультиколінеарності. Перевірку на гетероскедастчність проведено графічним методом (Gujarati, 1995; Zdrok \& Lagotskyi, 2010) (рис. 7-9). На графіках по осі абсцис відкладено 
значення незалежної змінної, а по осі ординат - квадрати відхилень фактичних значень $у$ від теоретичних (розрахованих за рівнянням регресії), $e^{2}$.

Аналіз рис. 7-9 показав відсутність систематичного зв'язку та низькі значення між величинами $X_{i}$ та відповідними квадратами відхилень $e^{2}$, що свідчить про відсутність гетероскедастичності або гомоскедастичність моделей фондовіддачі (7) і фондоозброєності (8). Однак дані рис. 10 показали високий рівень залежності між $x_{3}$ та квадратами відхилень $e_{3}^{2}, R^{2}=0,7961$, що свідчить про ймовірну гетероскедастичність моделі (9).

Для точного з'ясування питання щодо наявності гетероскедастичності, модель (9) перевірено за допомогою аналітичного тесту рангової кореляції Спірмена (Spearman's rank correlation test) (Gujarati, 1995; Zdrok \& Lagotskyi, 2010). Для цього розраховано коефіцієнт рангової кореляції Спірмена $r_{s}=0,8225$ і значення $t$-статистики $t=6,1365$, яке потрібно порівняти 3 табличним $t_{0,99: 18}=2,8$. Оскільки $t>t_{0,99 ; 18}$, то 3 довірчою ймовірністю $p=0,99$ підтверджено гіпотезу про наявність гетероскедастичності у моделі фондорентабельності (9).

Перевірку моделей (7)-(9) на наявність автокореляції проведено за допомогою $d$-тесту Дарбіна-Уотсона (Durbin-Watson d test) (Gujarati, 1995; Dougherty, 2011; Zdrok \& Lagotskyi, 2010). Для цього розраховано $d$-статистики: для моделі (7) $d_{1}=1,1822$; для моделі (8) $d_{2}=$ 0,62194 ; для моделі (9) $d_{3}=0,48095$. Табличні значення $d$-статистик за рівня значущості $a=0,05$ : для моделі (7): $d_{l}=1,100 ; d_{u}=1,537 ;$ для моделей (8) і (9): $d_{l}=1,201 ; d_{u}$ $=1,411$.

Висновки для моделі (7). Оскільки 1,10<1,182<1,537, то рішення щодо наявності або відсутності автокореляції прийняти неможливо (потрапляння у зону невизначеності, коли $H_{0}$-гіпотеза не приймається і не відхиляється). Висновки для моделей (8) і (9). Оскільки $0,62194<1,201$ i 0,48095<1,201, то існує додатна автокореляція.

Тестування моделі (7) на наявність мультиколінеарності проведено методом допоміжних регресій (Auxiliary Regressions) (Gujarati, 1995). Для цього побудовано допоміжну регресійну модель залежності між незалежними змінними $x_{2}$ та $x_{3}$ і визначено коефіцієнт детермінаціі $R_{23}^{2}$ та $F$-статистику:

$x_{2}=100,236+0,09366 \cdot x_{3}, R_{23}^{2}=0,6789 ; F=38,0538$. (10)

Табличне значення $F_{0,95 ; 1 ; 18}=4,41$. Оскільки 38,0538 $>4,41$, то існує мультиколінеарність. Проте вона у цьому випадку не $\epsilon$ серйозною проблемою, тому що значення коефіцієнта детермінаціі моделі (7) $€$ достатньо високим $\left(R^{2}=0,8482\right)$, а усі коефіцієнти регресії $\epsilon$ статистично значущими із значним перевищенням фактичних значень $t$-статистик над табличним (див. табл. 2).

Висновки. На прикладі типового лісового підприємства Малого Полісся побудовано три адекватні економетричні моделі. Перевірка моделей загалом за $F$ статистиками та параметрів моделей за $t$-статистиками показала позитивний результат 3 ймовірністю 0,95 . Крім цього, усі моделі перевірено на гетероскедастичність і автокореляцію, а перша модель фондовіддачі ще і на мультиколінеарність.
У першій моделі фондовіддачі наявна мультиколінеарність, але вона у цьому випадку не $є$ серйозною проблемою. Модель $є$ гомоскедастичною, а ії перевірка на автокореляцію дала невизначений результат. Отже, ця модель може бути використана для аналізу і прогнозування.

Друга модель фондоозброєності є гомоскедастичною, але в ній є додатна автокореляція. Тому модель доцільно використовувати тільки для аналізу. Її застосування також і для прогнозування стане можливим, якщо в ході подальших досліджень автокореляцію з моделі буде усунено.

У третій моделі фондорентабельності є гетероскедастичність та додатна автокореляція. Тому доцільно провести подальші дослідження для усунення гетероскедастичності та автокореляції або пом'якшення їх наслідків. У разі позитивного результату модель можна використати для аналізу і прогнозування.

Розроблені моделі можна використати для вдосконалення планування використання основних засобів лісогосподарських підприємств Малого Полісся. Запропоновану методику також можна використати для розроблення відповідних моделей для будь-якого лісогосподарського підприємства.

\section{Перелік використаних джерел}

Babeshko, L. O. (2006). Essencials of Econometric Modeling. (2nd ed.). Moscow: KomKniga. [In Russian].

Dougherty, C. (2011). Introduction to Econometrics. (4th ed.). New York: Oxford University Press.

Green, W. H. (2018). Econometric Analysis. (8th ed.). Stern School of Business, New York University: Pearson.

Gujarati, D. N. (1995). Basic Econometrics. (3rd ed.). New York: McGraw-Hill Book Company.

Henyk, O. V., Kozlovskyi, S. O., \& Henyk, Ya. V. (2011). Nature Reserve Fund of Ukraine: Modeling and Forecasting of Economic Activities. Lviv: UNFU, Liga-Press. [In Ukrainian].

Klebanova, T. S., Raievnieva, O. V., Prokopovych, S. V., Stepurina, S. O., Yatsenko, R. M., \& Chuyko, I. M. (2010). Economic and Mathematical Modeling. Kharkiv: PH "Engec". [In Ukrainian].

Kozlovskyi, S. O. (2005). Essencials of Econometrics. Lviv: UNFU. [In Ukrainian].

Larka, M. I., \& Horzhii, D. O. (2013). Reserves to Improve the Efficiency of Use of the Fixed Assets of the Enterprise. Visnyk of NTU "KhPI", 22(995), 38-43. [In Ukrainian].

Magnus, Ya. R., Katyshev, P. K., \& Peresetskii, A. A. (2005). Econometrics. Initial Course. (7th ed.). Moscow: Dielo. [In Russian].

Pelyukh, O. R., \& Zahvoyska, L. D. (2018). Investigation of Lviv region populations preferences regarding recreational forests using choice experiment method. Scientific Bulletin of UNFU, 28(9), 7380. https://doi.org/10.15421/40280915

Pindyk, R. S., \& Rubinfeld, D. L. (1998). Econometric models and Economic Forecasts. (4th ed.). New York: Irwin/McGraw-Hill Book Company.

Pokropyvnyi, S. F. (2006). Enterprise Economics. (3rd ed.). Kyiv: KNEU. [In Ukrainian].

Shvediuk, Yu. V. (2018). Evaluation of Economic Efficiency of Reforestation: Maley Polissya Case Study. Lviv: SPOLOM. [In Ukrainian].

Torosov, A. S., Zhezhkun, I. M., Kalashnikov, A. O., \& Kharchenko, Yu. V. (2018). Methodical approaches to determination of model forestry enterprises. Scientific Bulletin of UNFU, 28(9), 110-113. https://doi.org/10.15421/40280921

Zdrok, V. V., \& Lagotskyi, T. Ya. (2010). Econometrics. Kyiv: Znannia. [In Ukrainian]. 
O. V. Henyk, S. O. Kozlovskyi

Ukrainian National Forestry University, Lviv, Ukraine

\section{ECONOMETRIC MODELING OF INDICATORS OF EFFICIENCY}

OF USE OF FIXED ASSETS OF A FORESTRY ENTERPRISE

According to the indicators of a forestry enterprise typical for the Male Polissya of Ukraine, multiple regression models for such general indicators of the efficiency of the use of fixed assets as capital productivity, capital-labour ratio and fund profitability (dependent variables) were constructed. The authors have identified the most important factors (independent variables) influencing the value of dependent variables, which include as follows: the volume of wood harvesting, thousand cubic meters $\left(X_{1}\right)$; the volume of wood processing products, thousand UAH $\left(X_{2}\right)$; net income from sales of products, thousand UAH $\left(X_{3}\right)$; average monthly salary of employees of the enterprise, UAH $\left(X_{4}\right)$. A preliminary econometric analysis of models was carried out: correlation fields and graphs of dependence between all independent and dependent variables were constructed; pair coefficients of correlation were calculated, and the force (density) of the relationship between all variables of the models was evaluated as well. The analysis showed that factors of $X_{2}, X_{3}$ and $X_{4}$ significantly affected by capital productivity and capital-labour ratio, while the fund profitability is only the independent variables $X_{3}$ and $X_{4}$. The volume of wood harvesting $\left(X_{1}\right)$ is found not to affect all three dependent variables, and the volume of wood processing products $\left(X_{2}\right)$ is proved to have a weak effect on the fund profitability. With the help of stepwise regression analysis, namely, the stepwise removal of variables, adequate regression models were constructed. The significance of the models were generally estimated by Fisher's $F$-statistics, and the model parameters were estimated by Student's $t$-statistics with the confidence probability $p=0.95$. The final equation of capital productivity contains two independent variables $-X_{2}$ and $X_{3}$. The final equation of capital-labour ratio contains one independent variable $-X_{4}$. The final equation of fund profitability also contains only one independent variable $-X_{3}$. Models were tested for multicollinearity, heteroscedasticity and autocorrelation. The constructed models can be used to improve the planning of the use of fixed assets of the forest enterprises of Male Polissya. The proposed method can also be used to develop appropriate models for any forestry enterprise.

Keywords: capital productivity; capital-labour ratio; fund profitability; stepwise regression analysis. 